\title{
Eğitimde Program Değerlendirme Yaklaşımlarına Genel Bir Bakış
}

\section{A General View to Program Evaluation Approaches in Education}

\section{Zeynep DEMIRTAŞ ${ }^{* *}$}

Öz. Bu çalışmada, bir eğitim programının değerlendirilmesine dönük, alan yazında yer alan program değerlendirme yaklaşımlarından bazıları ele alınmıştır. Bir eğitim programının taslak, uygulama ve ürün olarak hedeflenen düzeye ne kadar ulaştığı, ulaşmamış ise eksik veya hatanın nerede olduğunu belirlemeye dönük yapılan çalışma, program değerlendirme olarak ifade edilebilir. Bu süreç, program geliştirmede bir zorunluluktur çünkü bir eğitim programı yeni gelişme, değişme, bilgi, anlayış, teknoloji gibi durumlardan etkilenen ve bu durumlara göre kendisini yeniden inşa etmek ya da güncellemek zorunda olan dirik bir yapıdır. Bu çerçevede, bir eğitim programının değerlendirilmesi, program geliştirme uzmanlarına, bilim uzmanlarına, öğretmenlere, yöneticilere, eğitim politikaları üretenlere, ailelere ve sivil toplum kuruluşları gibi pek çok paydaşa dönüt vermesi açısından önemli olduğu düşünülmektedir. Derleme yöntemi ile gerçekleştirilen çalışmada, alan yazında yer alan on program değerlendirme yaklaşımının temel özelliklerine yer verilmiştir.

Anahtar Kelimeler: Eğitim programı, program geliştirme, program değerlendirme, program değerlendirme yaklaşımları.

Abstract. In this study, some of the program evaluation approaches in literature directed to evaluation of a curriculum are investigated. Program evaluation is a study that investigates a program in terms of reaching the target level at what rate as draft, practice and product and it tries to find if it does not reach the target level, what the problem or deficiency is. It is a necessity for program evaluation. Because, a program is a system affected by situations as new developments, changes, data, perceptions, technology and it is a dynamic system that has to build or update itself according to these situations. In this context, a curriculum evaluation is important in terms of giving feedback to many partners as program development experts, scientists, teachers, managers, education policy makers, families, and nongovernmental organizations. This study is performed with collecting method and it represents basic features of ten program evaluation approaches in literature.

Keywords: Curriculum, program development, program evaluation, program evaluation approaches.

\begin{abstract}
Toplumsal Mesaj.
Eğitim programındaki yenilikler; ulusal ve uluslararası düzeyde yarışabilen ve ülkelerin ekonomik büyümesine katkı yapacak, bilimsel olarak okuryazar yurttaşlar yetiştirmek amacı ile yapılır. Bu yenilikler mevcut programların değerlendirilmesi ile gerçekleştirilir. Bu çalışmada bir eğitim programının değerlendirilmesine dönük alan yazında yer alan bazı program değerlendirme yaklaşımlarının teme özelliklerine yer verilmiştir.
\end{abstract}

\section{Public Interest Statement.}

Developments in curriculums are done for training literate citizens scientifically, who can compete at the national and international level and contribute the countries' economic growth. These developments occur with the evaluation of the present program. In this study, basic features of some of the program evaluation approaches in literature directed to evaluation of a curriculum are given place.

\footnotetext{
* Bu çalışma yazar tarafından Prof. Dr. Süleyman Çelenk danışmanlı̆̆ında hazırlanan "illköğretim Fen ve Teknoloji Dersi Öğretim Programının Uygulanma Sürecinin Değerlendirilmesi" başıılı doktora tez çalışmasından üretilmiştir ve VIII. Uluslararası Lisansüstü Eğitim Sempozyumunda bildiri olarak sunulmuştur.

** Sakarya Üniversitesi, Eğitim Fakültesi, Eğitim Programları ve Öğretim Bilim Dalı, zeynept@sakarya.edu.tr
} 


\section{Gíriş}

Öğrencilerin, istendik yönde nitelikli özellikler kazanmaları, eğitim kurumlarında etkili ve verimli öğrenme yaşantıları geçirmelerine bağlıdır. Eğitim programları çerçevesinde oluşturulan öğrenme ortamlarının aynı zamanda toplumsal ve bilimsel gelişmeleri de yansıtacak şekilde düzenlenmesi gerekmektedir. Bu bağlamda, eğitim sistemleri mutlaka planlı yapılmalıdır. Çünkü girdi, işlem, çıktı ve dönüt öğelerinden oluşan eğitim sistemi, açık bir sistemdir ve sürekli kendini yenileyen bir yapıdır. Bu nedenle, eğitim sistemlerinde, sürekli geliştirme, yenileme ve tekrar düzenlenme çalışmaları bir zorunluluktur. İşte bu yenilenme sürecinin nasıl ve ne yönde olması gerektiği, değerlendirme süreçlerinin etkin bir şekilde kullanılmasına bağlıdır. Bir diğer deyişle, değerlendirme, bir eğitim progrmanın taslak, süreç ve ürün aşamalarında, işelevselliğini ortaya koyma, eksiklerini belirleme ve giderme; işlemeyen ve hatalı yönlerini tespit etme ve onarma-düzeltme için yapılan işlemledir. Bu bağlamda, değerlendirme, (Bantwini, 2010), intiyaçları karşılama veya belirlenen boşlukları doldurma, hataları düzeltme, programı yeniden düzenleme ve güncelleme için vazgeçilmez bir araçtır. Çünkü yenilikler kaçınılmazdır ve eğitim programı zamanın taleplerini karşılayabilecek özellikte olmalıdır. Toplumsal ve bilimsel değişikliklerin sıkça yaşandığı çağımızda, eğitim programlarının da bu yönde düzenlenmesi bir gerekliliktir. Öz olarak, eğitimin niteliğinin artmasında, programların geliştirilmesi ve değerlendirilmesi büyük önem kazanmaktadır.

\section{AMAÇ VE YÖNTEM}

Bu çalışmada, bir eğitim programının değerlendirilmesine dönük, alan yazında yer alan program değerlendirme yaklaşımlarından bazılarının temel özelliklerinin ortaya konması amaçlanmıştır. Bu çerçevede, bu çalışmada, alanyazında yer alan ve ulaşılabilen program değerlendirme yaklaşımlarından on sınıflandırma ele alınarak, her bir program değerlendirme yaklaşımının genel özellikleri, program dğerlendirmeye bakış açısı ve değerlendirme aşamaları-boyutları öz olarak ortaya konulmuştur. Çalışma sonuçlarının, program geliştirme uzmanlarına, bilim uzmanlarına, öğretmenlere, yöneticilere, eğitim politikaları üretenlere, ailelere ve sivil toplum kuruluşları gibi ilgililere katkı sağlayacağı düşünülmektedir.

Çalışmada, araştırma yöntemi olarak derleme yöntemi kullanılmıştır. Derleme çalışmaları, belli bir alan ve konuda yapıımış olan çalışmaların sınıflandırılması ve değerlendirmesi özelliğini taşıyan çalışmalardır. Bu tür çalışmalar, alınyazında var olan bilgi birikiminin özet ve sentezini içeren bir yapıda yeniden oluşturulması süreçlerini kapsar. Bu süreç, alanyazındaki çalışmalara yeni bir yorum getirebilir, eski ve yeni yorumları birleştirebilir ya da belirli bir alandaki bilgi yapısını ortaya koyma amacıyla gerçekleştirilebilir. Derleme çalışmalarındaki amaç, başka araştırmacıların fikirleri, görüşleri ve yaklaşımlarının özetlenmesi ve bir sentez oluşturulmasıdır (Herdman, 2006).

\section{EĞiTiM PROGRAMI}

"Eğitim sistemleri eğitim programları ile işlerlik kazanır" (Erden, 1998: 2). Eğitim programı üzerine birçok tanım yapılmıştır. Varış (1988) eğitim programını bireylere, milli eğitimin ve eğitim kurumlarının amaçlarını kazandırmaya yönelik eğitim kurumlarında yapılan tüm faaliyetler olarak tanımlarken, Ertürk (1972), "yetişek" olarak nitelendirdiği eğitim programını hem eğitimci hem de öğrenci açısından değerlendirerek, öğrencilerin yetiştirilmesi için gerçekleştirilen eğitim yaşantılarının düzenlenmesi ile eğitimcilerin uyguladığı eğitim durumlarının planlanması şeklinde ifade etmiştir. Doğan (1974: 361) ise, kapsamlı bir şekilde ele aldığı eğitim programını, "öğrencide meydana gelen davranış değişikliğini, buna ulaşmak için öğrencinin karşı karşıya geleceği eğitim yaşantılarını, bunları faaliyete geçirebilmek için öğretim metotlarını ve amaca ne oranda ulaşıldığını ölçmek için ölçme araçlarını ve değerlendirme kıstaslarının belirlenmesi" şeklinde tanımlamıştır.

Eğitim programını, Oliver (1965), okulun sorumluluk alanına giren tüm yaşantılar ve bu yaşantıların gerçekleştirilmesini sağlayan öğretmenlerin çalışmaları sonucunda öğrencilerin karşı karşıya geldiği 
durumlar şeklinde ifade ederken, Saylor ve Alexander (1968), “okulun, okul içi ve dışındaki bütün durumlarda beklenen sonuçlara ulaşmak için giriştiği bütün çabalar" olarak tanımlamışlardır (Akt. Fidan, 1997:15). Tyler ve Taba ise, eğitim programını, "istendik amaçlara ulaşmak için stratejileri içeren bir eylem planı olarak ifade ederek, eğitim programında amaçlar, hedefler, konu alanı, öğretimin düzenlenmesi ve değerlendirme öğelerine ağırlık vermişlerdir" (Akt. Erden, 1998: 3). Stake (1967) eğitim programını; öğrencinin başarılı olması için öğretmenin neler yapması gerektiği ve öğrencinin neye maruz bırakılacağına yönelik amaçlar, içerik, öğrenme çevreleri, yöntemler ve bunların meydana getirdiği değişikliklerin karakterize edilmesi şeklinde ifade etmiştir.

Bütün tanımların ortak noktası eğitim ve öğrenme faaliyetlerinin bir plan ve program çerçevesinde yapılması gereğini ortaya koymaktır. Ayrıca bu süreç süreklilik gerektirmektedir. İşte bu süreklilik "program geliştirme" olarak adlandırılmaktadır.

\section{PROGRAM GELIŞTIRME VE DEĞERLENDIRME}

“Program geliştirme en geniş anlamıyla eğitim programlarının tasarlanması, uygulanması, değerlendirilmesi ve değerlendirme sonucu elde edilen veriler doğrultusunda yeniden düzenlenmesi süreci (Erden, 1998:4); gerek okul içinde ve gerekse okul dışında, Milli Eğitimin ve okulun amaçlarını etkinlikle geliştirmek ve gerçekleştirmek üzere düzenlenen muhteva ve faaliyetlerin, uygun yöntem, teknik, araç ve gereçlerle geliştirilmesine yönelmiş koordine çabaların tümüdür" (Varış, 1988:21). Ancak düzenlenen programın, masa başında değiştirilmesi, bir kısım konuların çıkarılması ya da eklenmesi değildir. Program geliştirme, operasyonel bir deyim olarak, süreçlerle ilgili olan bütün ilgililerin, malzeme, araç ve gereçlerin geliştirilmesi ile gerçekleşir (Varış, 1988:26-27).

Program geliştirme sürecinin en son ve en önemli ayağı olan değerlendirme ise, "gözlem ve çeşitli ölçme araçları ile eğitim programlarının etkililiği hakkında veri toplama, elde edilen verileri programın etkililiğinin işaretçileri olan ölçütlerle karşılaştırıp yorumlama ve programın etkililiği hakkında karar verme sürecidir" (Erden, 1998:10).

Değerlendirmede amaç; programın değeri üzerinde verilen kararlarda kullanılan verilerin başarılı bir şekilde toplanması ve analiz edilmesidir (Wood, 2001). Eğitimde değerlendirmenin amacı, eğitimcilere ve öğrencilere bilgi vermektir. Program değerlendirme, eğitim programıyla ilgili verilerin toplanmasını, işlenmesini ve yorumlanmasını gerektirir. Değerlendirmenin bütünüyle yapılması için iki türde verinin toplanması gerekir. Birincisi, programın amaçları, öğrenme çevresi, personeli, yöntemleri, içeriği ve çıktılarının nesnel olarak açıklanması, ikincisi ise bu amaçların, öğrenim ortamının vb. uygulanışlılığı ve kalitesi ile ilgili kişisel görüşlerin ve yargıların alınmasıdır. Bir değerlendirmeci, okul yaşantısının başlangıcında öğrencilerin ihtiyacı olan becerileri, belirlenmiş amacın toplumsal değerini, çalışmanın maliyetini belirleyerek, belirlenmiş hedeflere karşı eğitim kurumunun çıktılarını tartarak bir karşılaştırma yapmalıdır. Değerlendirmecinin bu çabaları, program hakkında daha iyi karar verilmesini, daha iyi program geliştirilmesini ve eğitim programının daha iyi kullanılmasını sağlar (Stake, 1967). Cronbach (1964), nitelikli öğretimin olası nedenlerini ve etkilerini incelemek için değişkenlerle birlikte ele alınması gerektiğini vurgular. Değerlendirmenin ana hedefi, gelecekteki eğitim programlarına yol göstermek amacıyla sürekli ilişkileri açıklamaktır. Öğrenci başarısı için öğretimin niteliği ve öğretim ile başarı arasındaki ilişkinin de açıklanması gerekir. Değerlendirme eğitim uygulamaları hakkındaki genellemeleri içerir (akt. Stake, 1977). Insanlar değerlendirmenin çok farklı amaçları başarmasını umut eder. Bu amaçlar: olayları belgelemek, öğrenci değişikliğini kaydetmek, kurumsal gerekliliği belirlemek, problemin sorumlusunu bulmak, yönetimin karar vermesine yardımcı olmak, düzeltici çalışmaları kolaylaştırmak, öğretimin ve öğrenimin anlaşılırlığını arttırmaktır. Bu amaçların her biri programın değeriyle doğrudan veya dolaylı yoldan ilgilidir ve özel bir program değerlendirme çalışması için bir amaç oluşturabilir. Değerlendirmede, her bir amacın ayrı ayrı verilere ihtiyacı olduğunun farkına varılması önemlidir (Stake, 2000:348). 


\section{PROGRAM DEĞERLENDIRME YAKLAŞIMLARI}

\subsection{Cronbach'ın (1982) Program Değerlendirme Yaklaşımları}

Cronbach (1982), program değerlendirme yaklaşımlarını bilimsel ve hümanistik olarak birbirine zıt iki şekilde ifade etmiştir. Bilimsel yaklaşımda tarafsız ve nesnel deneylerle değerlendirme yapılır. Gerçek bir deneyde iki veya daha fazla durumun yer alması halinde birbirini etkileme durumunun kontrol altına alınması, eşit grupların oluşturulmasında şartların kurumlar ya da kişiler tarafından değerlendirilmesi ve bütün katılımcıların aynı ürün ölçütlerini değerlendirmesi olmak üzere üç aşama yer almalıdır. Bilgi, nicel verilerden elde edilir ve istatiksel olarak analiz edilir. Veriler, farklı durumlarda öğrenci başarılarını karşılaştırmak için test sonuçlarından elde edilir. Değerlendirme ile elde edilen bilgilerin karşılaştırılması ile programlar hakkında kararlara varılır. Hümanistik yaklaşımda ise deneylerin yanlış bilgi verdiği düşünülmektedir. Program, kendi ortamında değerlendirilir. Faaliyet alanındaki gözlemler, fırsatları değerlendirici ve programla ilgili sorulan farklı sorulara cevap verici olarak yapılır. Araştırmada veriler nicel verilerden ziyade nitel veriler ile elde edilir. Değerlendirmeci, gözlemlere bağı kalır. Değerlendirmede, gözlemler ile gerçek olayların açıklanması ön plana çıkar. Naturalistik araştırma ile bilgiler, değerlendirmede yer alan katıımcılarla yapılan tartışma ve görüşmelerle toplanır (akt. Ornstein ve Hunkins, 1993: 328).

\subsection{Nevo'nun (1983) Program Değerlendirme Yaklaşımları}

Nevo (1983), eğitimde öne çıkan değerlendirme yaklaşımlarını on boyutta ele almıştır. Bu boyutları aşağıdaki sorularla açıklamıştır.

1. Değerlendirme nasıl tanımlanmalıdır? Eğitimsel değerlendirmede eğitim hedeflerinin tanımlanması ve hedeflerin değeri ve yararının değerlendirilmesi sistematik olmalıdır.

2. Değerlendirmenin fonksiyonları nedir? Eğitimsel değerlendirme dört farklı fonsiyona hizmet eder; (a) geliştirici (formative), (b) toplam (summative) (c) sosyopolitik (halkın desteğini kazanma ve motivasyon) ve (d) yönetimsel (bilirkişi çalışması).

3. Değerlendirmenin hedefleri nedir? Her şey bir değerlendirme hedefi olabilir. Eğitimde özel değerlendirme hedefleri öğrenciler, eğitim ve idari personel, eğitim programları, öğretim materyalleri, programlar, projeler ve kurumlarla ilgilidir.

4. Her bir hedef için ne tür bilginin toplanması gerekmektedir? Her hedef için toplanması gereken bilgi çeşitleri dört grupta incelenir: (a) hedefin amaçları, (b) hedefle ilgili stratejiler ve planlar, (c) hedefin uygulanma süreci ve (d) hedefin çıktıları ve etkileri.

5. Bir hedefin değerini değerlendirmede kullanılacak ölçüt ne olmalıdır? Bu ölçütler: (a) gerçek ve potansiyel müşterilerin intiyaçlarına cevap verme, (b) ulusal amaçlar, idealler ve sosyal değerleri başarma, (c) normlar ve standartlar üzerinde görüşme, (d) hedef için belirlenen amaçları başarma. Her hedef için çok ölçüt kullanılmalıdır.

6. Değerlendirme kime hizmet etmelidir? Değerlendirme hedefiyle ilgili olan bütün tarafların (paydaşlar) ihtiyaçlar bilgisine hizmet etmelidir. Değerlendirmeci, değerlendirmenin paydaşlarının bilgi ihtiyaçlarını betimlemekle yükümlüdür.

7. Değerlendirme süreci nasıldır? Bir değerlendirme süreci üç aktiviteyi içermelidir. Bunlar: (a) değerlendirme problemine odaklanma, (b) deneysel verileri toplama ve analiz etme ile (c) bulguların değerlendirmeyle ilgili kişilere bildirilmesidir.

8. Değerlendirmede hangi araştırma yöntemleri uygulanmalıdır? Belirlenmiş değerlendirme problemine göre davranış bilimlerinin birçok araştırma yöntemlerinden çalışmanın ilgili alanlarına uygun olanları kullanılır.

9. Değerlendirmeyi kim yapmalıdır? Değerlendirme bireysel ya da takım olarak yürütülebilir. Değerlendirmecilerin: (a) kapsamlı şekilde araştırma metodolojisi ve veri analizi tekniklerinde yeterli olmak, (b) değerlendirme hedefinin özünü ve sosyal içeriğini anlamlandırmak, (c) değerlendirme 
sürecinde gerekli olan kişilerle ve gruplarla doğru iletişim kurmak ve bunu sürdürmek ve (d) bahsedilen bu yetenekleri kavramsal çerçeve içerisinde bütünleştirmek özelliklerine sahip olması gerekmektedir.

10. Değerlendirmede yargıya varmada hangi standartlar olmalıdır? Değerlendirmede standartları en iyi şekilde dengelemek gerekir. Bu standartlar: (a) kullanışlılık (kullanma ve uygulamada), (b) hatasızlık (teknik açıdan yeterli olma), (c) geçerlilik (gerçekçi ve ölçülü) ve (d) uygunluktur (yasal ve etik olarak) (Nevo, 1983: 124-125).

\subsection{House'un (1990) Program Değerlendirme Yaklaşımları}

House'a (1990) göre, değerlendirme yaklaşımları, yapısal olarak tek parçalıdan (monolitik) çoğulcu (plüralist) görüşe doğru hareket etmektedir. Metodolojik olarak değerlendirmede, standart başarı testlerinin uygulandığı rastgele seçilen deney-kontrol grubu desenlerinin işe koşulduğu nicel yöntemlerden, daha fazla seçme olanağı tanıyan nitel araştırma yöntemlerine geçiş olmaktadır. Neticede değerlendirmede çoğulcu yaklaşım, çoklu yöntemleri, ölçümleri, ölçütleri, katılımcıların yaklaşımlarını ve görüşlerini ele almaktadır. Toplum içinde meydana gelen çoğulcu görüş birliğindeki değişikliği yansıtır. Metodolojik birlik ile beraber karışık (mixed) verilerin toplandığı yöntemler de savunulmaktadır (House, 1990: 24-25, 27).

\subsection{Scriven'ın (1967) Program Değerlendirme Yaklaşımları}

Scriven (1967) değerlendirmeyi içe yönelik (intrinsic) ve sonuca yönelik (pay off) değerlendirme olarak ikiye ayırmıştır. Eğitim programını bir araç gibi düşünerek, aracın çalışabilirliğini ortaya koymak için aracı oluşturan bütün parçalarda bir ön değerlendirmenin yapılması ve aracın kullanıldıktan sonra etkilerinin incelenmesi şeklinde değerlendirilmenin yapılması gerektiğini ileri sürmüştür (akt. Cunningham, 1973: 355). İçsel değerlendirmede program kendi özünde, belirli, birbirini izleyen içerik yönünden değerlendiriliyor. Iç̧erikle ilgili denemeler öneriliyor ve çeşitli materyaller işe koşuluyor. Program planındaki içeriğin, öğrencilerin öğrenmesi üzerinde etkili olacă̆ı düşüncesiyle programın değeri tanımlanıyor. Değerlendirmeciler tarafından program ne kadar iyi? Program amaçlarını gerçekleştirmede ne kadar başarılı olur? sorularına cevap aranıyor. iç̧erikle ilgili amaç ve hedeflerin değeri hakkında karar veriliyor (Ornstein ve Hunkins, 1993: 329-330). Eğitim programının özellikleri (amaç, içerik ve öğretmen eğitimi gereksinimleri) programın öğrenciler, öğretmenler ve toplum üzerindeki etkilerinden ayrı düşünülerek değerlendiriliyor (Posner, 1995:229). Sonuca yönelik değerlendirmede ürünler işlevsel olarak tanımlanarak, programın etkileri değerlendiriliyor. Programın sadece öğrenciler üzerinde değil öğretmenler, aileler ve yöneticiler üzerindeki etkileri de araştırılıyor. Bu yaklaşımda farklılığın belirlenmesinde ölçüt olarak, deneykontrol gruplarına yapılan ön test ve son testler ele alınıyor (Ornstein ve Hunkins, 1993: 329).

\subsection{Posner'ın (1995) Program Değerlendirme Yaklaşımları}

Posner'a (1995) göre, beş değerlendirme yaklaşımı vardır. Bunlar;

1. Geleneksel yaklaşım: Geleneksel eğitim programı, doğru bilgileri geri çağırmayı, temel becerilere hâkim olmayı ve geleneksel değerleri telkin etmeyi vurgular. Temel değerlendirme soruları, öğrencilerin bilgiyi elde edip etmediklerini, temel becerilere hâkim olup olmadıklarını ve kabul edilmiş değerleri özümseyip özümsemediklerini ölçmeye çalışır. Bu soruların cevaplanmasında; standart testlerin sonuçları, sınıfta öğrenciler tarafından verilen cevaplar, tamamlanan ödevlerin dakikliği ve intizamı, öğrencilerin öğretmenlerin talimatlarını takip etmedeki yetenek ve istekliliğinin karşılaştırılması yöntemleri kullanılır. Değerlendirmede; kabul edilen gerçek bilgilerin, becerilerin ve değerlerin etkili bir şekilde iletilip iletilmediğini belirlemek amaçlanır.

2. Deneysel yaklaşım: Deneysel eğitimin temel amacı, öğrencilerin eğitimsel yaşantılar/tecrübeler içinde gelişimine devam etmesidir. Değerlendirmede; öğrenciler üzerindeki deneysel programların kısa ve uzun vadeli etkileri nasıldır? sorusu sorulur. Deneysel eğitimciler, öğrencilerin sahip olduğu yaşantıların içsel niteliğiyle ilgilenirler. Eğitimsel yaşantılar, demokratik ve insancıldır, öğrencilerin merakını uyandırır ve onların girişimlerini arttırır. Deneysel eğitim programlarını değerlendirme yöntemleri çeşitlidir. Deneysel eğitim programları hem ürün temelli hem de içsel değerlendirme 
yaklaşımlarını gerektirir. Deneysel eğitim programları, programların etkililiğini belirlemek için ürün temelli değerlendirmeye, öğrencilerin sahip olduğu yaşantıların niteliğini belirlemede ise içsel değerlendirmeye intiyaç duyar.

3. Davranışsal yaklaşım: Davranışsal bir eğitim programında sonuçlanan becerilerin performansı dikkate alınır. Temel değerlendirme sorusu, öğrencilerin eğitim programında hedeflenmiş davranışları kazanıp kazanamadıklarıdır. Kullanılan yöntemlerde, nesnel ve niceliksel olarak değerlendirilen davranışın uygunluğu, öğretmen yapımı kalem-kağıt testleri, gözlemsel kontrol listeleri ve uygulamalı sınavlar ile belirlenir. Ölçüte başvurulan ölçümlerde öğrencilerin performansı dikkate alınır. Bu ölçümlerde, öğrencilerin birbirleriyle karşılaştırılmasından ziyade mutlak standartlar açısından başarıları değerlendirilir.

4. Disiplinlerin yapılandırılması yaklaşımı: Bu yaklaşım akademik disiplinlerin yapılandırılmasını vurgular. Değerlendirmede, öğrencilerin elde ettiği bilgiler, öğrencilerin araştırmalarda kullandığı soruşturmaların doğası, öğretilen içeriğin öğrenciler tarafından kavramsal yapılandırılması ölçmeye çalışılır. Sorular, öğrencilerin disiplinin kavramsal yapılarına karşı bir anlayış geliştirip geliştiremediklerini ve öğrencilerin gerçek bir araştırma yapıp yapmadıkları şeklindedir. Yöntemler, öğrencilerin problem çözmelerini, bilgiyi yorumlamalarını ve deneyler planlamalarını içerir.

5. Bilişsel yaklaşım: Bu yaklaşım öğrencilerin temel kavramları anlamasını ve düşünme becerilerini geliştirmesini vurgular. Değerlendirme soruları, öğrencilerin temel kavramları anlamlı bir şekilde öğrenip öğrenemediklerini ve problem çözme yöntemini kullanıp kullanamadıkları tarzındadır. Yöntemler, klinik görüşmeleri, öğrencilerin problem çözme becerilerinin ve yapılan hataların analizlerini ve kavram haritası egzersizlerini içerir. Bilişsel yaklaşımın nihai amacı, bireysel düşünme ve anlamlandırmanın nasıl olduğunu belirlemektir (Posner, 1995:231-232).

\subsection{Patton'un (1995) Program Değerlendirme Yaklaşımları}

Patton (1995), program değerlendirme yaklaşımlarını felsefi açıdan ele alarak, değerlendirme konularını sınıflandırmıştır. Bunlar:

1. Program katılımcılarının ve diğer paydaşların program tasarımında rol alması ve program değerlendirmenin birlikte yürütülmesi (katılımcı değerlendirme) ya da değerlendirmelerin uzmanlar tarafından yapılması (uzman temelli değerlendirme)

2. Değerlendirmede elde edilen bilgilerin somut, gözlemlenebilir ve ölçülebilir (insanlarla ilgili sayısal değerler-ailenin gelir düzeyinin artması, suç oranın azalması gibi) olması durumunda nicel verilere, programın özelliklerinin ve ürünlerinin sayısal olarak ölçülemediği durumlarda (programlar ve diğer kurumlar arasındaki işbirliği ya da güçlülük ve özsaygı hisleri gibi) nitel verilere başvurulması.

3. Değerlendirmeyi tarafsız ve nesnel değerlendirmecilerin yürütmesi (değer yargısı olmayan değerlendirme) ya da değerlendirmenin her zaman kişisel, mesleki ve politik inançlar ile değerlerin etkisi altında kalması (savunmacı değerlendirme) (akt. Douglah, 1998: 5).

\subsection{Stufflebeam'ın (1999) Program Değerlendirme Yaklaşımları}

Stufflebeam (1999), değerlendirme yaklaşımlarını dört kategoride sınıflandırmıştır.

Ilk kategori geçersiz ve eksik bulguların yer aldığı sözde değerlendirmeler yaklaşımıdır. Bu yaklaşım, halkla ilgili çalışmalar ve devlet kontrolündeki çalışmalar olmak üzere ikiye ayrılır. Bu değerlendirme yaklaşımlarında; programın gerçek değerine ve yararlıığına bakılmaksızın programla ilgili pozitif ve negatif görüşler yer almaktadır. Politik hedeflere göre kişiler ve/veya otoritenin kararı ile programın başarısı veya başarısızlığı ortaya konmaktadır. Bu yaklaşımlar, değerlendirme servislerinin güvenirliğini azaltmaktadır. Değerlendirmecilerin bu yaklaşımlara karşı dikkatli olmaları gerekir.

íkinci kategoride sorulara/yöntemlere yönelik yaklaşımlar yer alır. Bu yaklaşımlar, hedef temelli çalışmalar, ürün odaklı değerlendirmede maliyet çalışmaları, hedef sınama programları, ürünleri gözlemleme ve değerlendirme, performans değerlendirme, deneysel çalışmalar, yönetim bilgi sistemleri, maliyet-yarar analizi, aydınlatıcı görüşme, durum çalışması değerlendirmeleri, eleştiri ve 
uzmanlık yaklaşımı, program teorisi temelli değerlendirme ve karma yöntemlerin kullanıldığı çalışmalar olmak üzere on üç yaklaşımı içermektedir. Bu yaklaşımlarda yer alan çalışmalarda, programın değerini ve yararlıığını değerlendirmede sorular ile çözümler ele alınır ve buna göre tercih edilen yöntemler kullanııır. Bu çalışmalarda başlangıç noktası olarak işlevsel hedefler, standart ölçme araçları, maliyet analiz prosedürleri, uzman görüşü, bir program modeli ya da yöntemi, durum çalışması prosedürleri, yönetim bilgi sistemleri, deneysel desenler ile nitel ve nicel değerlendirmelerin yer aldığı karma yöntemler yer alır. Bu şekilde, verilen sorulara metodolojik olarak yeterli olan çözümler elde edilir.

Üçüncü kategoride, gelişmeden sorumlu değerlendirme yaklaşımları yer almaktadır. Bu yaklaşımlar, karar vermeye yönelik çalışmalar, müşteriye yönelik çalışmalar ve denklik yaklaşımları olarak üçe ayrılır. Bir programın değerini değerlendirmede intiyaç duyulan ölçütler ve soruların tamamı kapsamlı bir şekilde araştırılmaktadır. Programın değerini ve yararlıı̆̆ını belirleme de temel ölçütler olarak programın paydaşlarının değerlendirmelerine intiyaç duyulur. Program planlarında ve işlemlerinde yer alacak, teknik ve ekonomik açıdan uygun ölçütler araştırılır. Program hedefleriyle uyumlu olmayan ürünler de ele alınır. Programın yararı ve değeri kararında kusursuz, belgeye dayalı ve kesin değerlendirmelerin yer aldığı geniş çaplı araştırmalar yapılır. Genellikle, nitel ve nicel değerlendirme modelleri, araştırma sonuçlarının sağlamasının yapılması için birlikte kullanıır.

Dördüncü kategoride, doğrudan toplumsal gündemi ele alan yaklaşımlar yer almaktadır. Bu yaklaşımlar, müşteri merkezli çalışmalar, yapılandırmacı değerlendirme, katılımlı demokratik değerlendirme ve faydalanma/kullanım odaklı değerlendirme yaklaşımları olarak dörde ayrılır. Bu yaklaşımlarda, programların tanımlanması, araştııılması ve değerlendirilmesi aşamalarında uzmanlar kadar paydaşların bakış açıları da yer alır. Özellikle yapılandırmacı anlayış benimsenmiştir ve nitel yöntemler kullanılır. Paydaşların yorumlarından elde edilen bulgulara önem verilir (Stufflebeam, 1999:3-5).

\subsection{Fitzpatrick, Sanders ve Worthen'ın (2004) Program Değerlendirme Yaklaşımları}

Fitzpatrick, Sanders ve Worthen (2004), değerlendirme yaklaşımlarını altı kategoride açıklamıştır:

1. Hedeflere yönelik yaklaşımlar (objectives-oriented approaches), kazanılabilir ölçüde tanımlanmış belirli amaç ve hedefler üzerinde odaklanır.

2. Yönetime yönelik yaklaşımlar (management-oriented approaches), idari düzeyde karar vericilerin bilgi ihtiyaçlarının tahmin edilmesi ve belirlenmesi ile ilgilenir.

3. Müşteriye yönelik yaklaşımlar (consumer-oriented approaches), rekabet halinde olan eğitim programları, öğretim ürünleri vb. arasından seçim yapan eğitim müşterisi tarafından kullanmak üzere, açık olarak tanımlanmış eğitimsel ürünlerle ilgili gerekli bilgileri değerlendiriciye sağlamak için çalışır.

4. Uzmanlığa yönelik yaklaşımlar (expertise-oriented approaches), eğitimsel çalışmalarının kalitesini değerlendirmek için profesyonel/mesleki uzmanlığın doğrudan uygulanmasını savunur.

5. Eleştiriye yönelik yaklaşımlar (adversary-oriented approaches), değerlendirmenin merkezinde olan farklı değerlendirmecilerin (lehinde ve aleyhinde) bakış açılarındaki karşıtlık üzerinde durur.

6. Naturalistik ve katılımcıya yönelik yaklaşımlar (naturalistic and participant-oriented approaches), değerlendirmede verilerin, ihtiyaçların, ölçütlerin ve değerlerin belirlenmesinde katılımcıların (değerlendirmede yer alan paydaşlar) katıımı ve naturalistik araştırmanın gerekliliğini savunur (Fitzpatrick, Sanders ve Worthen, 2004: 60).

\subsection{Dart'ın (2004) Program Değerlendirme Yaklaşımları}

Dart (2004), program değerlendirmede normatif yaklaşımları altı kategoride incelemiş̧ir. Bunlar;

1. Deneysel yaklaşımlar: Bu yaklaşım, bilimsel araştırma sonucunda üretilen bilgi gibi değerlendirmeyi açıklamaktadır. İyi bir değerlendirmenin yapılması, deneysel veri ile teyit edilebilen bir program hakkındaki bilgi ve teori ile mümkündür. Deneylerin sonuçlarına mantıklı açıklamalar geliştirmek ve iç geçerliliği tehdit eden unsurları azaltma düşüncesi ile hareket edilmektedir. Burada 
temel görev, hipotez oluşturma ya da çıktıları oluşturan ' $Y$ ' ile buna etki eden ' $X$ ' arasındaki sabit bağlantıyı göstermektir. Değerlendirmede deneysel tasarımlarda, işlemler için program katıımcıları rastgele atanır, işlem grubu ve kontrol grubu bu şekilde belirlenir. Ayrıca, işlem sürecinden önceki ve sonraki değişikliklerin izlenebilmesi için ön test ve son test yapılır.

2. Test etme/sınama amaçlı yaklaşımlar: Bu yaklaşımlar bir programın belirtilen amaç ve hedeflerine ulaşılıp ulaşılmadığının belirlenmesine odaklanmıştır. Bu yaklaşımda iyi bir değerlendirme, öngörülen hedeflerin ulaşılma derecesini doğru bir şekilde belirlenmesine bağlıdır. Tyler (1967), değerlendirmeyi bir programın hedeflerine ne ölçüde ulaşıldığını belirleme süreci olarak tanımlamıştır. Bu yaklaşımda davranışsal olarak tanımlanmış hedefler ölçülmektedir. Bu nedenle öğretim girdileri yerine öğrenme çıktılarına odaklanılmaktadır. Önceden belirlenen hedeflerle değerlendirme yapıldığı için eğitim programının incelenmesi yerine öğrencilerin performansı ölçülmektedir.

3. Karar yönetimi yaklaşımları: Bu yaklaşımlar, karar verecek kişilerin programın organizasyonunu yönetmesinde intiyaç duydukları bilgileri karşılamayı amaçlamaktadır. Değerlendirme, organizasyon için yapılır. Bu yönetimin bir işlevidir. Değerlendirmenin amacı, programdan yararlanan bireyler ve toplumdan ziyade program yöneticilerine hizmet etmektir. Daha iyi yönetim kararları vermek için bilgi edinilir.

4. Yargıya dayalı yaklaşımlar: Uzmanların profesyonel kararını içeren bu yaklaşımlarda, bir programın yararlııı̆ı veya değerinin belirlenmesine yönelik kararlara ulaşııı. Değerlendirmede yarar ve değerin belirlenmesi karar verenler için önemlidir. Değerlendiriciler, programın ne gibi etkiye sahip olduğunu keşfetmek ve etkilerini, etkilenenlerin ihtiyaçlarıyla karşılaştırmak zorundadırlar. Değerlendirmede, öngörülen sonuçların incelenmesi için programın kendi hedeflerinin de ötesine bakılmalıdır, yani, beklenmedik sonuçlar da dikkate alınmalıdır. Bazı durumlarda, sonuçların değerini ve mantığını da sorgulamak gerekebilir. İyi bir değerlendirmede, programın etkisi, başarı ya da değer yargısı olarak ortaya çıkar.

5. Çoğulcu-Sezgisel Yaklaşımlar: Bu yaklaşımlar programla ilgili farklı paydaşların farklı görüşlerini içeren bakış açılarını değerlendirmeye dâhil eder. Değerlendirme tasarısına hangi ilgili kişilerin katılacağı belirlenir. Katılımcıların ortak görüş birliğine varmaları sağlanır. Karşııılı öğrenme ve kendi kendini yöneten bir durum söz konusudur.

6. Teori rehberli yaklaşımlar: Bu yaklaşımlar, program teorisi modellerinin yapılanmasını içerir. Bir programın ulaşımak istenen sonuçları nasıl elde etmeyi amaçladığını ayrıntılı bir şekilde ortaya koyar. Program teorisi 'bir programın nasıl işleyeceği konusunda uygun ve mantıklı bir model oluşturulması' olarak tanımlanır. İyi bir değerlendirme, yalnızca bir programın neden işe yarayıp yaramadığını sormanın ötesine geçmelidir; özellikle hangi programların hangi durumlarda çalıştığını incelemelidir (Dart, 2004).

\subsection{Guyadeen ve Seasons'ın (2016) Program Değerlendirme Yaklaşımları}

Guyadeen ve Seasons (2016), program değerlendirmede normatif yaklaşımları dört kategoride ele almışlardır.

1. Katılıma yönelik (Participatory) değerlendirme: Eğitim programının paydaşlarını değerlendirme sürecine dahil eder. Paydaşlar, değerlendirme sürecinde, değerlendirme tasarımında, veri toplama, veri analizi ve iletişimin her aşamasında yer almaktadır. Paydaşlara yetki verilen bu süreçte her bir paydaş kendi görevini yerine getirir ve yerel olarak yapılan uygulamaları incelerler.

2. Yetkilendirmeye yönelik (Empowerment) değerlendirme: Topluluklara kendi performanslarını izlemelerine ve değerlendirmelerine olanak tanıyan araçlar ve bilgiler sağlanır. Bu şekilde değerlendirme sonuçlarından daha fazla yararlanılarak toplumsal gelişim süreci desteklenir.

3. İşbirliğine yönelik (Collaborative) değerlendirme: Program geliştirme sürecine katkıda bulunmak için yararlanılan değerlendirme sonuçlarını elde etmede, program geliştirme ekibinin verimini 
arttırma amacıyla program geliştirme ekibi ile değerlendirme takımı birlikte çalışır. Bu süreçte program değerlendirmenin ayrıntılarını yansıtmaya yönelik oluşturulmuş değerlendirme tasarımı yönetilir. Aynı zamanda paydaşların birbirlerine daha fazla destek vermeleri sağlanır.

4. Gelişime yönelik (Developmental) değerlendirme: Program geliştirme ekibine eş zamanlı ya da hemen hemen eş zamanlı geri bildirim sağlanarak, devam eden gelişim döngüsüne katkı sağlanır. Bu son derece karmaşık ve sürekli değişen çevreler için kullanışlıdır Guyadeen ve Seasons, 2016).

\section{SONUÇ VE ÖNERILER}

Çalışmada özellikleri ortaya konulan program değerlendirme yaklaşımlarının, farklı sınıflandırmalar altında olmasına rağmen, çoğunlukla benzer özelliklere sahip oldukları görülmektedir. Bu özellikler şöyle sıralanabilir:

1- Genel olarak bilimsel ve hümanistik değerlendirme yaklaşımlarının (Cronbach, 1982) diğer değerlendirme yaklaşımlarını kapsadıkları söylenebilir. Bilimsel yaklaşımlar, nicel araştırma yöntemleri ile yapılan değerlendirme sürecini ifade ederken, hümanistik yaklaşımlar nitel araştırma yöntemleri ile yapılan değerlendirme çalışmalarını belirtmektedir. Bu nedenle nicel ve nitel yöntemlerle programların değerlendirilmesini içeren diğer değerlendirme yaklaşımları bilimsel ve hümanistik değerlendirme yaklaşımları kapsamında olduğu söylenebilir.

2- Araştırma yöntemi olarak deneysel araştırma yöntemini öneren program değerlendirme yaklaşımları, programın başarısını öğrencilerin performansına göre ön-test son test sonuçları açısından değerlendirmeyi belirtmektedir. Ĕgitim programını hedefler boyutunda ve/veya çıktı-ürünsonucun değerlendirilmesi açısından ele alan yaklaşımlarda bu yöntem kullanılmaktadır. Bu duruma, tek parçalı (monolitik) değerlendirme yaklaşımı (House, 1990), sonuca yönelik değerlendirme yaklaşımı (Scriven, 1967), deneysel yaklaşım (Dart, 2004; Posner, 1995) ve davranışsal yaklaşım (Posner, 1995) örnek olarak verilebilir. Bir eğitim programını birçok açıdan değerlendirmeyi öneren yaklaşımlar hem nicel hem de nitel araştırma yöntemlerinin uygulanması gerektiğini vurgulamaktadır. Bu yaklaşımlar, çoğulcu (plüralist) yaklaşım (House, 1990), sorulara/yöntemlere yönelik ve gelişmeden sorumlu değerlendirme yaklaşımları (Stufflebeam, 1999) ve Patton'un (1995) felsefi açıdan üç boyutta sınıflandırdığı program değerlendirme yaklaşımlarıdır.

3- Çalışmada yer verilen program değerlendirme yaklaşımlarında paydaşların rolünü vurgulayan yaklaşımlar çoğunluktadır (Dart, 2004; Fitzpatrick, Sanders ve Worthen, 2004; Guyadeen ve Seasons, 2016; House, 1990; Nevo, 1983; Patton, 1995; Scriven, 1967; Stufflebeam, 1999). Yaklaşımlarda paydaşlar, programa katılanlar ve programdan kısa ve uzun vadede etkilenen diğer paydaşlar olmak üzere iki şekilde kategorize edilmektedir. Bununla birlikte bazı yaklaşımlarda değerlendirmede, paydaşların yanı sıra müşteri kavramına da vurgu yapılmaktadır. Örneğin, Nevo (1983) programın, gerçek ve potansiyel müşterinin ihtiyacına cevap verecek şekilde değerlendirme ölçütlerinin belirlenmesinden, Stufflebeam (1999) müşteri merkezli değerlendirme çalışmalarının yapılması gerektiğinden ve Fitzpatrick, Sanders ve Worthen da (2004) müşteriye yönelik program değerlendirme yaklaşımından ayrıca söz etmektedir. Paydaşlar arasında özellikle uzmanların program değerlendirme üzerindeki etkilerini ön plana çıkaran yaklaşımlarda vardır. Bunlar, uzman temelli değerlendirme (Patton, 1995), sorulara/yöntemlere yönelik yaklaşımlar içinde yer alan eleştiri ve uzmanlık yaklaşımı (Stufflebeam, 1999), uzmanlığa yönelik yaklaşımlar (Fitzpatrick, Sanders ve Worthen, 2004) ve uzmanların profesyonel kararını içeren yargıya dayalı yaklaşımlardır (Dart, 2004). Paydaşlara yönelik program değerlendirmeyi toplumsal açıdan nitelendiren değerlendirme yaklaşımları da bulunmaktadır. Programın toplum üzerindeki etkilerini belirlemeyi amaçlayan içe yönelik değerlendirme (Scriven, 1967), halka hizmet eden değerlendirme fonksiyonu (Nevo, 1983), toplumda çoğunluğun benimsediği görüşleri ve bu görüşlerdeki değişimi inceleyen çoğulcu yaklaşım (House, 1990), toplumsal gündemden etkilenen yaklaşımlar (Stufflebeam, 1999) ve toplumsal gelişimi desteklemeyi amaçlayarak değerlendirmede toplumun her kesiminden bireylere yetki veren 
yetkilendirmeye yönelik değerlendirme yaklaşımları (Guyadeen ve Seasons, 2016) örnek olarak verilebilir.

4- Çalışma kapsamındaki program değerlendirme yaklaşımlarının bir kısmında ise program değerlendirmenin program yöneticilerine katkı sağlaması adına yapılması gerektiği ifade edilmektedir. Bu yaklaşımlar, bireyler ve toplumun yanı sıra program yöneticileri için bilgi edinmeyi sağlayan karar yönetimi yaklaşımları (Dart, 2004), programla ilgili idare düzeyindekilere bilgi sağlamak için yapılan yönetime yönelik yaklaşımlar (Fitzpatrick, Sanders ve Worthen, 2004) ve değerlendirme fonksiyonlarını bilirkişi çalışması olarak belirten yönetimsel (Nevo, 1983) yaklaşımlardır.

Çalışma sonuçlarına dayalı ve gelecek araştırmacılara dönük şu öneriler getirilebilir: 1- Bu çalışmada ortaya konulan program değerlendirme yaklaşımlarının hangi durumlarda etili olarak kullanılabileceğine dönük çalışmalar yapılmalıdır. 2- Bu çalışmada yer verilen program değerlendirme yaklaşımlarından hangilerinin, Türkiye'deki eğitim programlarını değerlendirmede işlevsel olarak kullanılabileceğini ortaya koyan çalışmalar yapılmalıdır. 3- Program değerlendirme yaklaşımları ve program değerlendirme modelleri arasındaki ilişkililik ve birlikte uygulanabilirliğine dönük çalışmalar yapılmalıdır. 4- Alan yazında yer alan diğer program değerlendirme yaklaşımlarının özelliklerini ortaya koyan çalışmalar yapılmalıdır.

\section{Kaynakça}

Bantwini, B. D. (2010). How Teachers Perceive The New Curriculum Reform: Lessons From a School District in The Eastern Cape Province, South Africa. International Journal of Development, 30, 8390.

Cunnigham, D. J. (1973). Evaluation of Replicable Forms of Instruction a Classification of Information Needs in Formative and Summative Evaluation. AV Communication Review, 21(3), 351-367.

Dart, J. (2004). Six Normative Approaches to Evaluation. www.semanticscholar.org/paper/SixNormative-Approaches-to-Evaluation-Dart adresinden 10.12.2017 tarihinde erişilmiştir.

Doğan, H. (1974). Program Geliştirmede Sistem Yaklaşımı. Ankara Üniversitesi Eğitim Bilimleri Fakültesi Dergisi, 7(1), 361-385.

Douglah, M. (1998). Developing a Concept of Extension Program Evaluation. http://learningstore.uwex.edu/pdf/G3658-7.PDF adresinden 05.01.2012 tarihinde erişilmiştir.

Erden, M. (1998). Eğitimde Program Değerlendirme (3. Baskı). Ankara: Anı Yayıncılık.

Ertürk, S. (1972). Eğitimde Program Geliştirme. Ankara: Yelkentepe Yayınları.

Fidan, N. (1997). Eğitim Psikolojisi-Okulda Öğrenme ve Öğretme. Ankara: Alkın Yayınevi.

Fitzpatrick, J. L., Sanders, J. R. ve Worthen, B. R. (2004). Program Evaluation-Alternative Approaches and Practical Guidelines (3. Edit). Boston: Allyn \& Bacon Publisher.

Guyadeen, D. ve Seasons, M. (2016). Evaluation Theory and Practice: Comparing Program Evaluation and Evaluation in Planning. Journal of Planning Education and Research, 1-13, DOI: $10.1177 / 0739456 \times 16675930$.

Herdman, E. A. (2006). Guidelines for Conducting a Literature Review and Presenting Conference Papers. Hemşirelikte Eğitim ve Araştırma Dergisi, 3(1), 2-4.

House, E. R. (1990). Trends in Evaluation. Educational Researcher, 19(3), 24-28.

Nevo, D. (1983). The Conceptualization of Educational Evaluation. Review of Educational Research, 53(1), 117-128.

Ornstein, A. C. ve Hunkins, F. P. (1993). Curriculum Foundations, Principles and Issues (2. Baskı). Boston: Allyn and Bacon.

Posner, G. J. (1995). Analyzing The Curriculum. New York: McGraw Hill Inc. 
Stake, R. E. (1967). Toward a Technology Fort He Evaluation of Educational Programs. R. Tyler, R. Gagne ve M. Scriven (eds.), Perspectives of Curriculum Evaluation (ss. 1-12) içinde, Chicago: Rand McNally.

Stake, R. E. (1977). The Countenance of Educational Evaluation. A. A. Bellack ve H. M. Kliebard (eds.), Curriculum and Evaluation (ss. 372-390) İçinde, Berkeley: CA McCutchan.

Stake, R. E. (2000). Program Evaluation, Particularly Responsive Evaluation. D. L. Stufflebeam, G. F. Madaus ve T. Kelleghan (eds.), Evaluation Models (ss. 341-362) İçinde, Boston: Kluwer Academic Publishers.

Stufflebeam, D. L. (1999). Foundational Models for 21st Century Program Evaluation. Canada: The Evaluation Center Occasional Papers Series.

Wood, B. B. (2001). Stake's Countenance Model: Evaluation an Environmental Education Professional Development Course. The Journal of Environmental Education, 32(2), 18-27.

Varış, F. (1988). Eğitimde Program Geliştirme Teori ve Teknikler (4. Baskı). Ankara: Ankara Üniversitesi Eğitim Fakültesi Yayınları No: 157. 


\section{Extended Summary}

It is a necessity to organize learning environments, which are formed in the frame of curriculums, in such a way that represent social and scientific developments. There are so much social and scientific developments in the era and it is found necessary to arrange the curriculums according to the developments. Curriculum development and evaluation has a great importance to enhance the quality of curriculums. The aim of evaluation in education is to give information educators and students. Program evaluation requires collecting, processing and interpreting the data related to curriculum. People hope that curriculum can achieve many different goals. These goals are: authenticating developments, recording student evolution, identifying corporate essentials, finding responsible individuals of problems, helping management to decide, making corrective and preventive actions, enhancing comprehensibility of teaching and learning. Each of the goals is related to program's value directly or indirectly and each of them can be a goal for a special program evaluation study. Each goal needs respective data for evaluation and to be aware of this situation is important (Stake, 2000:348).

In this study, some of the program evaluation approaches in literature directed to evaluation of a curriculum are investigated. Program evaluation is a study that investigates a program in terms of reaching the target level at what rate as draft, practice and product and it tries to find if it does not reach the target level, what is the problem or deficiency. It is a necessity for program evaluation. Because, a program is a system affected by situations as new developments, changes, data, perceptions, technology and it is a dynamic system that has to build or update itself according to these situations.

\section{Purpose and Methodology}

In this study, it is aimed to reveal the basic characteristics of some of program evaluation approaches for the curriculum evaluation. In this framework, in this study, it is examined ten evaluation approaches of the general characteristics of each program evaluation approach, the point of view of the program evaluation, and the evaluation phases-dimensions. In this context, study results will provide giving feedback to many partners as program development experts, scientists, teachers, administrator, education policy makers, families, and nongovernmental organizations. In study, litarature method was used as research method.

\section{Program Evaluation Approaches}

Cronbach (1982), expressed program evaluation approaches in two different incompatible types as scientific and humanistic. Nevo (1983), discussed prominent evaluation approaches in education in ten dimensions. He expressed these dimensions in the form of questions. These are; 1 . How should be identified evaluation? 2. What are the functions of evaluation? 3. What are the targets of evaluation? 4. What kind of data should be collected for each target? 6 . To whom should the evaluation be served? 7. How is the evaluation process? 8 . Which research method should be used for evaluation? 9. Who should do the evaluation? 10. Which standards should be taken into account when judging? According to House (1990), evaluation approaches evolves from monolithic view to multipartite view structurally. Scriven (1967) separated evaluation two as intrinsic evaluation and result oriented evaluation. According to Posner (1995), there are five evaluation approaches. These are; 1. Traditional approach, 2. Experimental approach, 3. Behavioral approach, 4. Structuring disciplines approach, 5. Cognitive approach. Patton (1995), classified evaluation subjects by discussing evaluation approaches philosophically. These are: 1. Participant-based or expert-based evaluation, 2. Quantitative and qualitative referenced evaluation and 3. Value-free evaluation or defensive evaluation. Stufflebeam (1999), classified evaluation approaches in for categories. These are; 1 . Supposed evaluation approaches (2 approaches), 2. Questions/ methods directed approaches (13 approaches), 3. Approaches that determine the criteria of evaluating program's value (3 approaches) and 4. Approaches that discuss social agenda (4 approaches). 
Fitzpatrick, Sanders and Worthen (2004), explained evaluation approaches in six categories: 1.Objectives-oriented approaches, 2. Management-oriented approaches, 3. Consumer-oriented approaches, 4. Expertise-oriented approaches, 5. Adversary-oriented approaches), 6. Naturalistic and participant-oriented approaches. Dart (2004) investigated normative approaches in program evaluation in six categories. These are; 1. Experimental approaches, 2. Testing/tryout purposeful approaches, 3. Decision management approaches, 4. Judgment-based approaches, 5. Pluralistintuitional approaches, 6. Theory guiding approaches. Guyadeen and Seasons (2016) discussed normative approaches in program evaluation in four categories. 1. Participatory oriented evaluation, 2. Empowerment oriented evaluation, 3. Collaboration oriented evaluation, 4. Development oriented evaluation.

\section{Conclusion and Suggestions}

Despite the fact that program evaluation approaches in this study are in different classifications, it is seen that they commonly have similar features. These features can be put in order like this:

1- In general, it can be said that scientific and humanistic evaluation approaches (Cronbach, 1982) involve other evaluation approaches. While scientific approaches express the evaluation process that made with quantitative methods, humanistic approaches express the evaluation process that made with qualitative methods. Therefore, it can be said that scientific and humanistic evaluation methods involve the other evaluation approaches, which evaluate programs with qualitative and quantitative methods.

2- Program evaluation approaches, which suggest experimental research technique as research method, state the program's success according to students' performance in terms of pretestposttest conclusions. This method is used in the approaches that discuss the curriculum in terms of targets and/or evaluating output-product-result. Monolithic evaluation approach (House, 1990), result oriented evaluation approach (Scriven, 1967), experimental approach (Dart, 2004; Posner, 1995) and behavioral approach (Posner, 1995) can be shown as examples to this situation. The approaches, which suggest evaluating a curriculum in many aspects, emphasize the necessity of applying both quantitative and qualitative research methods. These approaches are, pluralistic approach (House, 1990), question/methods oriented and developmentally responsible evaluation approaches (Stufflebeam, 1999) and Patton's (1995) program evaluation approach, which he classified in three dimensions philosophically.

3- Approaches that emphasize the role of stakeholders are the majority in the program evaluation approaches in the study (Dart, 2004; Fitzpatrick, Sanders ve Worthen, 2004; Guyadeen ve Seasons, 2016; House, 1990; Nevo, 1983; Patton, 1995; Scriven, 1967; Stufflebeam, 1999).

4- In some of the program evaluation approaches in this study, it is stated that program evaluation should be made for contributing program managers.

Based on the research findings and directed following researchers, these suggestions can be offered:

1- Studies should be done on that in which situations the program evaluation approaches in this study can be used effectively. 2- Studies should be done on that which ones of the program evaluation approaches in this study can be used functionally for evaluating the curriculums in Turkey. 3- Studies directed relationality and applicability together between program evaluation approaches and program evaluation models should be done. 4- Studies that present the features of the other program evaluation approaches in the literature should be done. 